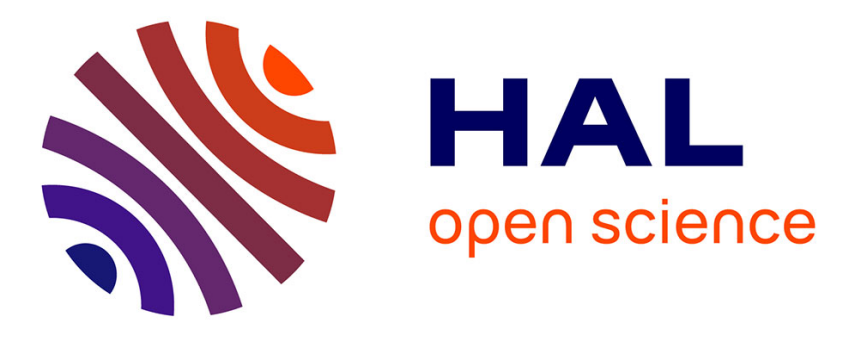

\title{
Analysis of the Teashirt Target Genes in Ureteric Bud Development
}

\author{
Laurent Fasano, Irene Sanchez-Martin, Xavier Caubit
}

\section{To cite this version:}

Laurent Fasano, Irene Sanchez-Martin, Xavier Caubit. Analysis of the Teashirt Target Genes in Ureteric Bud Development. Seppo Vainio. Kidney Organogenesis Methods and Protocols, 1926, Springer, pp.223-232, 2019, Methods in Molecular Biology, 978-1-4939-9020-7. 10.1007/978-1-49399021-4_18. hal-02048084

\section{HAL Id: hal-02048084 https://hal.science/hal-02048084}

Submitted on 4 Mar 2020

HAL is a multi-disciplinary open access archive for the deposit and dissemination of scientific research documents, whether they are published or not. The documents may come from teaching and research institutions in France or abroad, or from public or private research centers.
L'archive ouverte pluridisciplinaire HAL, est destinée au dépôt et à la diffusion de documents scientifiques de niveau recherche, publiés ou non, émanant des établissements d'enseignement et de recherche français ou étrangers, des laboratoires publics ou privés. 


\section{“Kidney Organogenesis: Methods and}

\section{Protocols"}

special Springer book on Methods of Molecular Biology (MMB)

\section{Genes controlling renal development}

42. Analysis of the teashirt target genes in ureteric bud development

Laurent Fasano*, Irene Sanchez-Martin and Xavier Caubit

Aix Marseille Univ, CNRS, IBDM, Marseille, France.

Correspondence should be addressed to L.F. (laurent.fasano@univ-amu.fr)

Running title/head: $T s h z$ : teashirt genes

\section{i. Summary/Abstract}

Microarrays and RNA-seq (RNA sequencing) are powerful technics to assess transcript abundance in biological samples and to improve our understanding of the relationship between genotype and phenotype. $T s h z 3^{+/-}$heterozygous mouse is a model for a human $19 \mathrm{q} 12$ syndrome 
characterized by autistic traits and renal tract defects [1]. To unravel renal tract pathological mechanisms, we took advantage of $T s h z 3$ mouse and performed comparative genome-wide expression profiling on embryonic ureter and/or kidney.

\section{ii. Key Words}

Microarray, RNA-seq, mouse, ureter, kidney, $T s h z 3$

\section{Introduction}

During the last three decades, the rapid development of genomic tools has offered the possibility to perform genome-wide analyses to identify changes associated with gene mutation in human and model organisms. In particular, transcriptomic analyses using microarrays and RNA-seq have improved our understanding of the molecular and cellular mechanisms occurring during the normal and pathological development of different model systems.

Historically, miniaturized microarrays prepared by high-speed robotic printing of complementary DNAs on glass began in the mid-1990s [2] and the first complete eukaryotic genome was placed on DNA chip in 1997 [3]. Since its first research use, different innovations (i.e. fabrication, robotics, informatics and bioinformatics) have dramatically improved the efficiency of microarray and reduced the cost of this technology. Nowadays and despite the improvements mentioned above, microarrays are challenged by RNA-seq, a high-throughput DNA sequencing method, allowing mapping and quantifying transcriptomes [4-6]. Indeed, RNA-seq, which uses next generation sequencing (NGS) technologies, presents several advantages compare to microarray. It does not depend on existing knowledge about genome sequence (in other words “you don't need to know what you sequence"), it has very low background, 
it allows quantification of expression levels, it is highly accurate and results are very reproducible.

Both microarrays and RNA-seq have revolutionized the way we probe whole-genome transcriptome, enabling us to generate, analyse and explore the transcriptome for a number of species, organs and cell types. In developmental biology, these technologies are methods of choice to profile differentially expressed genes between different experiment conditions (i.e. healthy $v s$. mutant tissues; time point $1 v s$. time point 2), which allow understanding transcriptomic dynamics in time and space, and comparison between mutant and normal conditions.

We combined mouse genetics and gene expression profiling to provide new insight into the role of differential gene expression in normal and pathological renal tract development. More specifically, we took advantage of Teashirt 3 (Tshz3) mutant mice that exhibit congenital junction obstruction (PUJO) with defective smooth muscle differentiation and absent peristalsis in the proximal ureter [7,8]. PUJO affects $0.3 \%$ of human births and in human, TSHZ3 is expressed in peri-urothelial cells of the proximal ureter and renal pelvis [9]. More recently, TSHZ3 was identified as a gene candidate for a syndrome characterized by autistic traits and renal tract defects [1]. Therefore, deciphering the molecular functions of $T s h z 3$ would be valuable to understand the basis of this syndrome. To this aim, we combined mouse genetics and gene expression profiling to provide new insight into the role of differential gene expression in normal and pathological renal tract development. We used microarray to evaluate up-regulated or down-regulated genes in $T s h z 3^{\text {lacZ/lacZ }}$ mutant ureters at mouse Theiler stage 22 (TS22; Embryonic stage (E) 14.5) and at TS24-25 (E16.5). At E14.5, which corresponds to the onset of the myogenic program and at E16.5, when smooth muscle cells (SMCs) express the full repertoire of differentiation marker 
genes. Recently, we have examined the differences in mRNA expression in TS20

(E12.5) Tshz $3^{\text {lacZ/lacZ }}$ mutant ureters and/or kidneys using RNA-seq.

\section{Materials}

\subsection{Dissection and sample collection}

1. Dissecting microscope with transillumination from bellow and fiber-optic from above.

2. Petri dishes $(35 \mathrm{~mm}$ or $65 \mathrm{~mm})$ filled with silicone

3. Disposable plastic container with disposable stir stick

4. Tungsten needles inserted into a needle holder

5. Dissecting instruments: Scissors, microdissecting scissors and forceps

6. Phosphate-buffered saline (PBS; 1X). To prepare 1 liter (L) of $1 \mathrm{x}$ PBS, dissolve 8 $\mathrm{g}$ of $\mathrm{NaCl}, 0.2 \mathrm{~g}$ of $\mathrm{KCl}, 1.44 \mathrm{~g}$ of $\mathrm{Na}_{2} \mathrm{HPO}_{4}, 0.24 \mathrm{~g}$ of $\mathrm{KH}_{2} \mathrm{PO}_{4}$ in $800 \mathrm{~mL}$ of $\mathrm{H}_{2} \mathrm{O}$. Adjust the $\mathrm{pH}$ to 7.4 with $\mathrm{HCl}$. Add $\mathrm{H}_{2} \mathrm{O}$ to $1 \mathrm{~L}$ (see Note 1).

7. Liquid nitrogen or dry ice (see Note 2).

\section{2 mRNA isolation}

1. Lab protocol for mRNA isolation or kit/reagents from your favourite manufacturer.

2. Ad hoc machines to control RNA quality, integrity and purity (see Note 3).

3. $26 \mathrm{G}$ needles

4. Eppendorf tubes

5. RNase-, DNase- and protease-free molecular grade water (see Note 3).

\section{Methods}




\subsection{Dissection and sample collection}

1. $T s h z 3$ mutant and wild-type kidneys and ureters were collected at E12.5 for RNAseq and at E14.5 and E16.5 for microarrays.

2. For the dissection, embryos were placed on petri dishes $(35 \mathrm{~mm}$ or $65 \mathrm{~mm})$ containing a silicone pad and covered with 1x PBS (see Note 4).

3. Dissections were performed mainly as described in "Dissection of embryonic mouse kidney, culture in vitro, and imaging of the developing organ" [10] and "Mouse urogenital development: a practical approach" [11]. For E12.5 samples, we adapted the protocol to improve the speed of the dissection (see Note 5).

4. E12.5 samples were placed in an Eppendorf directly in liquid nitrogen (see Note 2) and keep frozen at $-80{ }^{\circ} \mathrm{C}$ until RNA extraction. Upon dissection, E14.5 and E16.5 ureters were immediately drop into ready-to-use reagent for the isolation of total RNA according to manufacturer's instructions.

\section{2 mRNA isolation}

1. Tissue was homogenized using a 26-gauge needle attached to a sterile plastic syringe.

2. Total RNA was extracted using a RNA extraction kit according to manufacturer's instructions. The procedure allows 1) to lyse the tissue with a denaturing guanidineisothiocyanate-containing buffer, which inactivates RNAses to prevent RNA degradation; 2) to eliminate the DNA, ribosomal RNA and tRNA (see Note 6).

3. The integrity of RNA was assessed using a chip-based capillary electrophoresis machine and RNA concentration determined using a full spectrum $(220-750 \mathrm{~nm})$ spectrophotometer (see Note 3).

[Insert Figure 1 \& Figure legend in this chapter]

\subsection{Data acquisition microarrays}

1. Label protocol: cRNAs for hybridisation to "Provider A" arrays were prepared 
from 100 ng total RNA using the wild-type expression kit from "Provider A".

2. Hybridization protocol: Labelled-cRNA was fragmented and hybridised to mouse gene arrays (Provider A) following manufacturer's protocols. Three independent RNA preparations (triplicate) from the four different conditions [wild type and mutant at E14.5; wild type and mutant at E16.5] were processed and hybridised on Mouse Gene Arrays.

3. Data processing: Arrays have been quantile-normalize with respect to the probe GC content using the RMA algorithm (GC contend adjustment, RMA background correction and mean probe set summarization). Not or low expressed transcripts have been removed by a maximum expression cutoff $<100$. The data filtering result in 173,540 of 234,872 probe sets and 22,495 meta-probe sets. After normalization the arrays have been checked for outlier using the principal component analysis using a correlation dispersion matrix and normalized Eigenvector scaling. No outlier has been detected. Differential expression of summarized gene level expression was calculated using the Partek two way ANOVA statistic followed by a FDR multiple testing correction. Resulting p-values and FDR values indicating the probability of differential expression in state (wild type / knock out), stage (embryonic stages 14 and 16). 2240 transcript clusters with an ANOVA FDR $<0.05$ in one of the conditions (state, stage, state*stage interaction) have been defined as the significant differential expressed subset.

\section{Analysis \& interpretation}

We have four conditions that we can compare: E14.5 WT, E16.5 WT, E14.5

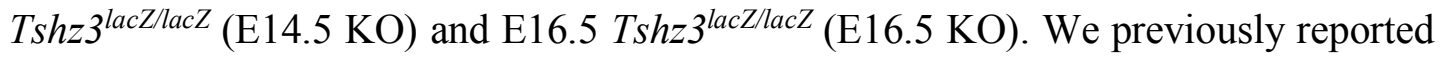
that myocardin (Myocd), a master regulator of the smooth muscle gene expression[12], was not expressed in the $T s h z 3^{\text {lacZ/lacZ }}$ mutant ureteral mesenchyme[7]. We used Myocd 
as an internal control (see Note 7). In both E14.5 Tshz $3^{\text {lacZ/lacZ }}$ compared to E14.5 WT (E14.5 KO vs. WT) and in E16.5 Tshz $3^{\text {lacZ/acZ }}$ compared to E16.5 WT (E16.5 KO vs. WT) ureters, Myocd showed the third strongest down-regulation; Thus for these two conditions, statistically significant $(\mathrm{p}<0.05)$, differentially expressed genes (DEGs) were consider for future investigation (see Note 7). Among the 22,495 genes present on the mouse genechip, we identified 2311 DEGs in WT E16.5 vs. E14.5 and 3614 genes in KO E16.5 vs. E14.5. Using an absolute fold change cut off value of 1 in $\log _{2}$ scale we identified 1112 down-regulated and 1199 up-regulated genes in WT E16.5 vs. E14.5 and 1851 down-regulated and 1763 up-regulated genes in KO E16.5 vs. E14.5. To characterize the dynamic regulation of gene expression we used Venny2.1[13]. This approach allowed comparing the gene expression patterns and showed that the absence of $T \operatorname{sh} z 3$ leads to a massive modification of gene regulation. The two conditions identified 4206 DEGs. 2049 being up-regulated and 2163 down-regulated. 15.7\% of the DEGs were unique to WT E16.5 vs. E14.5 (302 up-regulated and 359 downregulated) and 46\% were exclusively found in KO E16.5 vs. E14.5 (858 up-regulated and 1076 down-regulated). 38.2\% were common to both conditions (883 up-regulated and 722 down-regulated). Lastly, only 6 genes showed inverted patterns: 4 were up in WT and down in KO and, 2 were down in WT and up in KO (see Note 8).

[insert here the Figure 2 and its accompanying legend]

\subsection{Data acquisition RNA-seq}

1. Random primed cDNA library: Starting material: $1 \mu \mathrm{g}$ Total mRNA (minimum 500ng); Concentration > 20 ng/ $\mu$ l); Purity: OD 260/280: 1.8; RNA Integrity Number $(\mathrm{RIN}) \geq 8$ (see Note 3). Dissolved in RNase-, DNase- and protease-free molecular grade water (see Note 9). To obtain two independent total RNA samples from the two different conditions (wild type: WT1 \& WT2; mutant: KO1 \& KO2) we dissected and 
pooled a minimum of 8 ureters in each preparation. Upon purification, poly-A containing mRNA were fragmented and cDNA were prepared by randomprimed synthesis.

\section{Sequencing:}

Run type: pair end; read length: 2 x 50 bp.

Sample (S) WT1, Sequenced reads (SR) 38,564,100; S WT2, SR 52,609,430; S KO1, SR 65,805,700 and S KO2, SR 49,445,500

\section{Data processing:}

The raw data (sequences; fastq format) (see Note 10) were mapped to the mm10 version of the mouse genome to generate Sequence Alignment/Map (SAM/BAM) format. SAM is a tab-delimited alignment format consisting of a header section and an alignment section with 12 columns. BAM is the compressed, indexed and binary version of SAM format. SAM/BAM are also essential and precious, because this is what is mapped and hence used to count reads. After normalization, analysis of differentially expressed genes (DEGs) was performed using both the Bioconductor package DESeq/DESeq2 and the package edgeR. This analysis generated differential expression lists with False Discovery Rates (FDRs), which are derived from p-values corrected for multiple testing using the Benjamini-Hochberg method. 6 files in total were generated: FDR 1\%, 5\%, 10\% for both UCSC (transcripts) and ENSEMBL (genes).

\subsection{Analysis \& interpretation of RNA-seq data}

These data are currently under investigation to validate potential differentially expressed genes (DEGs) using in situ hybridization (ISH), immunodetection and/or qRT-PCR

\section{Notes}


1. Dispense the solution into aliquots and sterilize them by autoclaving for 20 minutes at $15 \mathrm{psi}(1.05 \mathrm{~kg} / \mathrm{cm} 2)$ on liquid cycle or by filter sterilization. Store at room temperature. You can also follow the same protocol to prepare a 10X PBS stock solution using $80 \mathrm{~g}$ of $\mathrm{NaCl}, 2 \mathrm{~g}$ of $\mathrm{KCl}, 14.4 \mathrm{~g}$ of $\mathrm{Na}_{2} \mathrm{HPO}_{4}, 2.4 \mathrm{~g}$ of $\mathrm{KH}_{2} \mathrm{PO}_{4}$.

2. Because of its properties (extremely cold (boiling point $-196^{\circ} \mathrm{C}$ ), small volumes vaporize to give large volumes of gas (1 litre gives $0.7 \mathrm{~m}^{3}$ of gas) which will displace oxygen in air) liquid nitrogen can cause sever burn-like damage to the skin and the low temperature of the vapour can cause damage to softer tissues (e.g. eyes, lungs), it is highly recommended to know how to transport and handle liquid nitrogen.

3. To determine RNA quantity and purity the best way is to measure UV absorption of sample using a spectrophotometer requiring $1-2 \mu 1$ of sample. Ideally, this spectrophotometer contains preset programs RNA measurements that automatically read the OD at 260,280 and 230 . The concentration of the RNA can be determined by measuring the $\mathrm{OD}_{260}$. A solution of RNA whose $\mathrm{OD}_{260}=1$ contains $\pm 40 \mu \mathrm{g}$ of RNA per milliliter. The $\mathrm{OD}_{260} / \mathrm{OD}_{280}$ ratio is an indication of the level of protein contamination in your sample. Pure RNA has an $\mathrm{OD}_{260} / \mathrm{OD}_{280}$ ratio of $2.1\left(1.8<\mathrm{OD}_{260} / \mathrm{OD}_{280}<2.0\right.$ are considered acceptable). Depending on the isolation protocol you used to extract RNA, your sample can also contains contaminant (e.g. guanidine salts, phenol). A high peak at $\mathrm{OD}_{230}$ indicates contamination. $1.5<\mathrm{OD}_{260} / \mathrm{OD}_{230}$ is considered as an ideal ratio.

Remember the best measurements are obtained 1) when RNA is solubilized in Tris EDTA (TE) buffer, 2) the blank solution is the same solution the RNA 
is diluted in and 3) RNA concentration below $20 \mu \mathrm{g} / \mathrm{mL}$ does not give reliable measurements.

To check for RNA integrity the best is to use a Bioanalyzer using a small amounts of RNA (1-2 $\mu \mathrm{L})$. Moreover, the analyzer determines an RNA Integrity Number (RIN) to standardize between RNA samples. These apparatus are expensive. If you don't have access to an analyzer, you can still run the RNA on a $1 \%$ standard agarose gel and examine the ribosomal RNA (rRNA). mRNA runs between the 2 ribosomal bands $(28 \mathrm{~S}-18 \mathrm{~S}$ in eucaryotic cells; $23 \mathrm{~S}-16 \mathrm{~S}$ in bacteria cells) and might be seen as a smear. A smear below the lower rRNA band (18S or $16 \mathrm{~S}$ ) suggests that the RNA is of poor quality. If you find that your RNA is degraded, you should prepare new RNA for your experiment.

4. To prepare the pad, use a disposable plastic container and a stir stick to make the elastomer (silicone) according to the manufacturer's instructions. Pour the elastomer into petri dishes, filling them a third to half way through. Let dry the dishes covered for \pm 24 hours at room temperature.

5. For dissecting the E12.5 kidney/ureter we cut embryos below the upper arms to keep the posterior half. We eliminated all the structures except the gonads and renal tract that are attached to the back. Kidneys and ureters were dissected using forceps and/or needles and put in an Eppendorf tube using a small spoon.

6. RNA purification should follow tissue isolation as quickly as possible. If not possible immersed the tissues in a RNA stabilization solution or froze them (i.e. liquid nitrogen; dry ice) to prevent alteration in the transcript profile. Samples for a given experiment should be collected following the same 
protocol.

7. We noticed that Myocd levels were not significantly affected in E16.5 WT compared to E14.5 WT (WT E16.5 vs. E14.5) ureters, suggesting that at E14.5 Myocd expression has already reached a plateau. This result was also observed in E16.5 Tshz $3^{\text {lacZ/lacZ }}$ compared to E14.5 Tshz3 $3^{\text {lacZ/lacZ }}$ (KO E16.5 vs. E14.5) ureters. For these two conditions, in order to keep Myocd in our analysis, we had to use a $\mathrm{p}<0.057$ in E14.5 KO vs. WT and $\mathrm{p}<0.055$ in E16.5 KO vs. WT, indicating that in vivo data could be helpful to choose a threshold when performing a global analysis.

8. The data mentioned here are accessible through GEO Series accession number GSE43940 at:

(http://www.ncbi.nlm.nih.gov/geo/query/acc.cgi?acc=GSE43940).

9. The best is probably to buy a RNase-, DNase- and protease-free molecular grade water from a provider. Otherwise you should use "ultra pure" MilliQ (reverse osmosis purified) water or double distilled water. Add $1 \mathrm{ml}$ DEPC (Diethylpyrocarbonate) per $1 \mathrm{~L}$ of water (i.e. to a final concentration $0.1 \%$ ). Mix thoroughly and let incubate for 12 hours at $37^{\circ} \mathrm{C}$. Autoclave DEPC-mixed water for 15 minutes. DEPC inactivates RNases by covalent modification and $0.1 \% \mathrm{DEPC}$ is probably sufficient to inactivate most RNase contamination (the efficacy of the DEPC in inactivating the RNase depends on the concentration of RNase but increasing the concentration of DEPC can affect the quality of RNA). The autoclaving step inactivates the DNases and removes all traces of DEPC.

10. One backup copy of the raw data (sequences) should be kept preciously and never use for analysis. 
1. Caubit X, Gubellini P, Andrieux J, Roubertoux PL, Metwaly M, Jacq B, Fatmi A, Had-Aissouni L, Kwan KY, Salin P, Carlier M, Lieden A, Rudd E, Shinawi M, VincentDelorme C, Cuisset JM, Lemaitre MP, Abderrehamane F, Duban B, Lemaitre JF, Woolf AS, Bockenhauer D, Severac D, Dubois E, Zhu Y, Sestan N, Garratt AN, Kerkerian-Le Goff L, Fasano L (2016) TSHZ3 deletion causes an autism syndrome and defects in cortical projection neurons. Nature Genetics 48 (11):1359-1369. doi:10.1038/ng.3681

2. Schena M, Shalon D, Davis RW, Brown PO (1995) Quantitative monitoring of gene expression patterns with a complementary DNA microarray. Science 270 (5235):467-470

3. Lashkari DA, DeRisi JL, McCusker JH, Namath AF, Gentile C, Hwang SY, Brown PO, Davis RW (1997) Yeast microarrays for genome wide parallel genetic and gene expression analysis. Proc Natl Acad Sci U S A 94 (24):13057-13062

4. Mortazavi A, Williams BA, McCue K, Schaeffer L, Wold B (2008) Mapping and quantifying mammalian transcriptomes by RNA-Seq. Nat Methods 5 (7):621-628. doi: $10.1038 /$ nmeth.1226

5. Nagalakshmi U, Wang Z, Waern K, Shou C, Raha D, Gerstein M, Snyder M (2008) The transcriptional landscape of the yeast genome defined by RNA sequencing. Science 320 (5881):1344-1349. doi:10.1126/science.1158441

6. Wilhelm BT, Marguerat S, Watt S, Schubert F, Wood V, Goodhead I, Penkett CJ, Rogers J, Bahler J (2008) Dynamic repertoire of a eukaryotic transcriptome surveyed at single-nucleotide resolution. Nature 453 (7199):1239-1243. doi:10.1038/nature07002

7. Caubit X, Lye CM, Martin E, Core N, Long DA, Vola C, Jenkins D, Garratt AN, Skaer $\mathrm{H}$, Woolf AS, Fasano L (2008) Teashirt 3 is necessary for ureteral smooth muscle differentiation downstream of SHH and BMP4. Development 135 (19):3301-3310. doi:135/19/3301 [pii]

10.1242/dev.022442

8. Martin E, Caubit X, Airik R, Vola C, Fatmi A, Kispert A, Fasano L (2013) TSHZ3 and $S 0 X 9$ regulate the timing of smooth muscle cell differentiation in the ureter by reducing myocardin activity. PLoS One 8 (5):e63721.

doi:10.1371/journal.pone.0063721

9. Jenkins D, Caubit X, Dimovski A, Matevska N, Lye CM, Cabuk F, Gucev Z, Tasic V, Fasano L, Woolf AS (2010) Analysis of TSHZ2 and TSHZ3 genes in congenital pelviureteric junction obstruction. Nephrol Dial Transplant 25 (1):54-60 10. Costantini F, Watanabe T, Lu B, Chi X, Srinivas S (2011) Dissection of embryonic mouse kidney, culture in vitro, and imaging of the developing organ. Cold Spring Harb Protoc 2011 (5):pdb prot5613. doi:10.1101/pdb.prot5613 11. Staack A, Donjacour AA, Brody J, Cunha GR, Carroll P (2003) Mouse urogenital development: a practical approach. Differentiation; research in biological diversity 71 (7):402-413. doi:10.1046/j.1432-0436.2003.7107004.x 12. Wang Z, Wang DZ, Pipes GC, Olson EN (2003) Myocardin is a master regulator of smooth muscle gene expression. Proc Natl Acad Sci U S A 100 (12):7129-7134. doi:10.1073/pnas.1232341100 
1232341100 [pii]

13. Oliveros JC (2007-2015) Venny. An interactive tool for comparing lists with Venn's diagrams. http://bioinfogpcnbcsices/tools/venny/indexhtml 


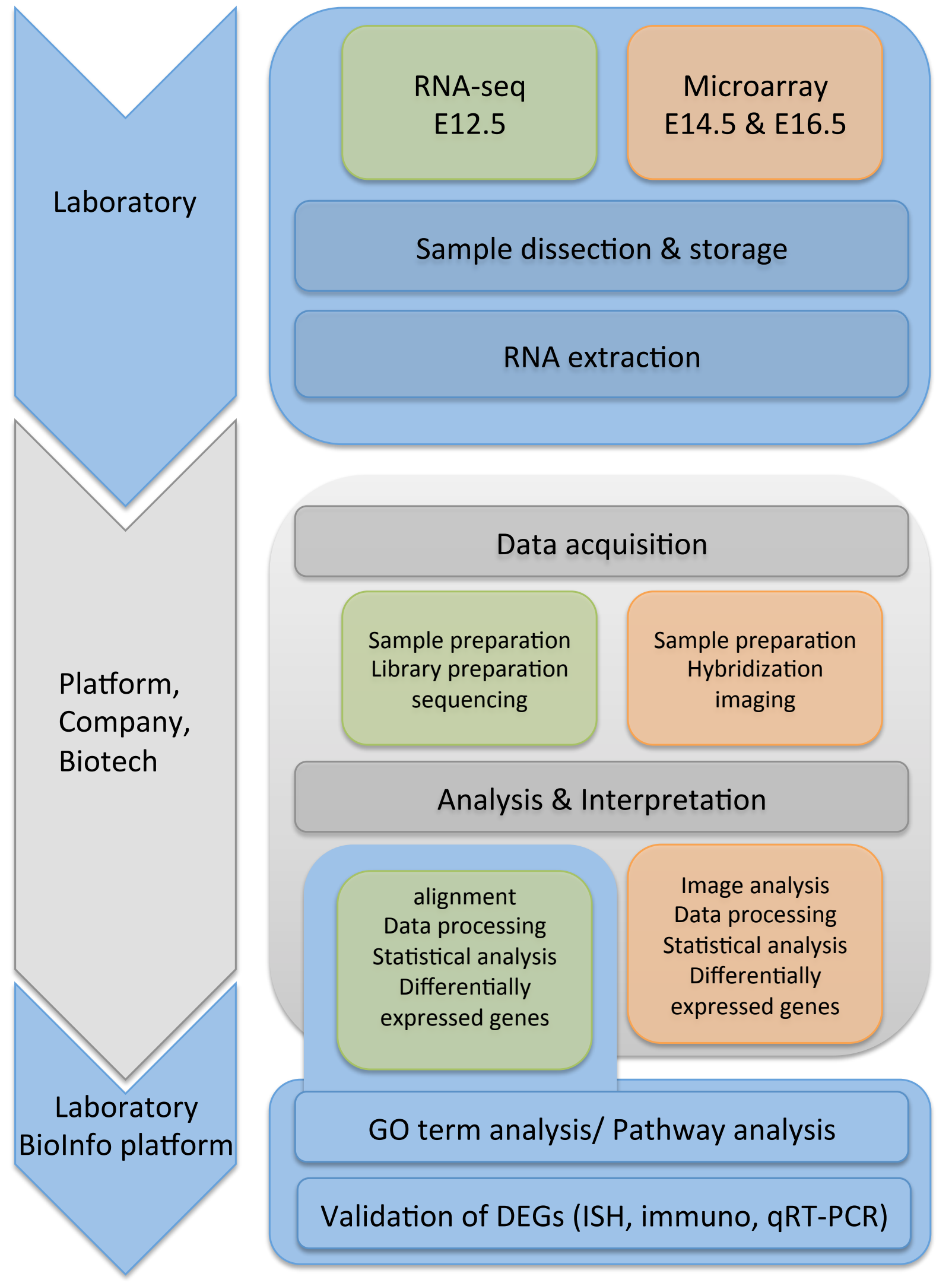

Fig. 1 Workflow of samples for RNA-seq (left) and microarray (left) 


\section{6vs14WT up 16vs14KO down}

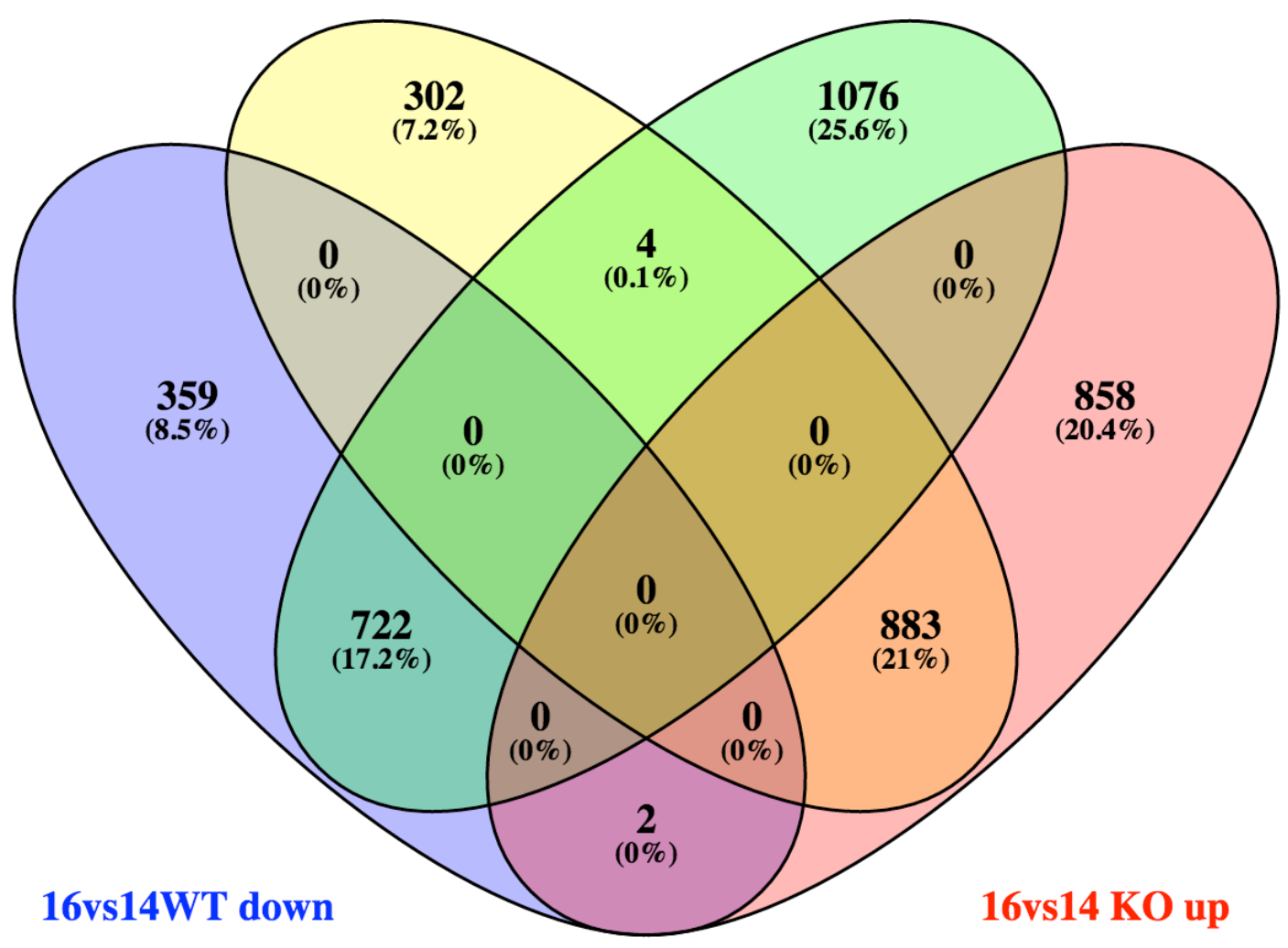

Fig. 2 Differentially expressed genes in wild-type and mutant ureters. Statistically significant differentially expressed genes in the comparison made between WT E16.5 vs. E14.5 and KO E16.5 vs. E14.5 